International Journal of Electrical and Power Engineering 5 (3): 144-149, 2011

ISSN: 1990-7958

(C) Medwell Journals, 2011

\title{
Modeling and Simulation of a Matrix Converter/Inductive Load System
}

\author{
Ibrahim A.M. Abdel-Halim, Hamed G. Hamed and Ahmed M. Hassan \\ Department of Electrical Engineering, Faculty of Engineering, Benha University, \\ 108 Shoubra St., Cairo, Egypt
}

\begin{abstract}
In this study, a system composed of a matrix converter and an inductive load is modeled and simulated using Matlab/Simulink software package. The modulation techniques used for the matrix converter are Venturini and Optimum venturini methods. The voltages and currents waveforms of the system are presented and compared to those obtained from previously published results to validate the simulation process.
\end{abstract}

Key words: Matrix converter, inductive load, Matlab/Simulink, Venturini and Optimum venturini methods, Egypt

\section{INTRODUCTION}

The matrix converter is a direct $\mathrm{AC}-\mathrm{AC}$ converter which uses an array of controlled bidirectional switches to create a controllable output voltage system with unrestricted frequency (Alesina and Venturini, 1981, 1989; Arevalo, 2008; Arevalo et al., 2010; Bradaschia et al., 2009; Cardenas et al., 2009; Huber and Borojevic, 1995; Imayavaramban et al., 2006; Shephered and Zhang, 2004; Vargas et al., 2009, 2010; Wheeler et al., 2002). Recently, matrix converters receive a lot of attention because they have several advantages such as they have simple and compact power circuit, generation of load voltage with arbitrary amplitude and frequency can be obtained, they operate with nearly sinusoidal input and output currents with harmonics only around or above the switching frequency, operation with unity input displacement factor for any load can be obtained and they have bidirectional power flow (Alesina and Venturini, 1981, 1989; Arevalo, 2008; Arevalo et al., 2010; Bradaschia et al., 2009; Cardenas et al., 2009; Huber and Borojevic, 1995; Imayavaramban et al., 2006; Shephered and Zhang, 2004; Vargas et al., 2009, 2010; Wheeler et al., 2002).

Few investigations have used Matlab/Simulink for simulation of the matrix converter to obtain its performance when used in some applications (Altun and Sunter, 2003; Sunter and Altun, 2005; Imayavaramban et al., 2006). However, either the transfer ratios were calculated by $m$-file in Matlab (Imayavaramban et al., 2006) or a simplified solution algorithm (Altun and Sunter, 2003; Sunter and Altun, 2005) was used. In this study, Matlab/Simulink package is used to simulate the matrix converter in detail when venturini and optimum venturini modulation techniques (Wheeler et al., 2002; Arevalo, 2008) are used. The matrix converter is loaded by an inductive static load.

\section{MATERIALS AND METHODS}

Matrix converter model: Figure 1 shows a simplified representation of a matrix converter system. It consists of nine bidirectional power switches which are controlled to connect the input 3-phase voltage source to a 3-phase load. Controlling of these switches is achieved according to a certain modulation strategy.

The modulation strategy is based on a desired output voltage magnitude and frequency and an input displacement factor (Alesina and Venturini, 1981, 1989; Arevalo, 2008; Huber and Borojevic, 1995; Imayavaramban et al., 2006; Shephered and Zhang, 2004; Wheeler et al., 2002). The matrix converter will be modeled by its output voltages and input currents in terms of switching functions of the switches as follows:

$$
\begin{aligned}
& {\left[\begin{array}{l}
\mathrm{v}_{\mathrm{a}}(\mathrm{t}) \\
\mathrm{v}_{\mathrm{b}}(\mathrm{t}) \\
\mathrm{v}_{\mathrm{c}}(\mathrm{t})
\end{array}\right]=\left[\begin{array}{lll}
\mathrm{S}_{\mathrm{Aa}}(\mathrm{t}) & \mathrm{S}_{\mathrm{Ba}}(\mathrm{t}) & \mathrm{S}_{\mathrm{Ca}}(\mathrm{t}) \\
\mathrm{S}_{\mathrm{Ab}}(\mathrm{t}) & \mathrm{S}_{\mathrm{Bb}}(\mathrm{t}) & \mathrm{S}_{\mathrm{Cb}}(\mathrm{t}) \\
\mathrm{S}_{\mathrm{Ac}}(\mathrm{t}) & \mathrm{S}_{\mathrm{Bc}}(\mathrm{t}) & \mathrm{S}_{\mathrm{Cc}}(\mathrm{t})
\end{array}\right]\left[\begin{array}{l}
\mathrm{v}_{\mathrm{A}}(\mathrm{t}) \\
\mathrm{v}_{\mathrm{B}}(\mathrm{t}) \\
\mathrm{v}_{\mathrm{C}}(\mathrm{t})
\end{array}\right]} \\
& {\left[\begin{array}{l}
\mathrm{i}_{\mathrm{A}}(\mathrm{t}) \\
\mathrm{i}_{\mathrm{B}}(\mathrm{t}) \\
\mathrm{i}_{\mathrm{C}}(\mathrm{t})
\end{array}\right]=\left[\begin{array}{lll}
\mathrm{S}_{\mathrm{Aa}}(\mathrm{t}) & \mathrm{S}_{\mathrm{Ab}}(\mathrm{t}) & \mathrm{S}_{\mathrm{Ac}}(\mathrm{t}) \\
\mathrm{S}_{\mathrm{Ba}}(\mathrm{t}) & \mathrm{S}_{\mathrm{Bb}}(\mathrm{t}) & \mathrm{S}_{\mathrm{Bc}}(\mathrm{t}) \\
\mathrm{S}_{\mathrm{Ca}}(\mathrm{t}) & \mathrm{S}_{\mathrm{Cb}}(\mathrm{t}) & \mathrm{S}_{\mathrm{Cc}}(\mathrm{t})
\end{array}\right]\left[\begin{array}{l}
\mathrm{i}_{\mathrm{a}}(\mathrm{t}) \\
\mathrm{i}_{\mathrm{b}}(\mathrm{t}) \\
\mathrm{i}_{\mathrm{c}}(\mathrm{t})
\end{array}\right]}
\end{aligned}
$$

The switching functions in Eq. 1 and 2 are defined as follows (Huber and Borojevic, 1995; Wheeler et al., 2002):

$$
\begin{aligned}
\mathrm{S}_{\mathrm{Kj}} & =\left\{\begin{array}{llll}
1, & \text { switch } & \mathrm{S}_{\mathrm{Kj}} & \text { closed } \\
0, & \text { switch } & \mathrm{S}_{\mathrm{Kj}} & \text { open }
\end{array}\right. \\
\mathrm{K} & =\{\mathrm{A}, \mathrm{B}, \mathrm{C}\}, \mathrm{j}=\{\mathrm{a}, \mathrm{b}, \mathrm{c}\}
\end{aligned}
$$

In order to avoid short-circuited input terminals and open-circuited output phases, these switching functions

Corresponding Author: Ibrahim A.M. Abdel-Halim, Department of Electrical Engineering, Faculty of Engineering, Benha University, 108 Shoubra St., Cairo, Egypt 
Int. J. Elec. Power Eng., 5 (3): 144-149, 2011

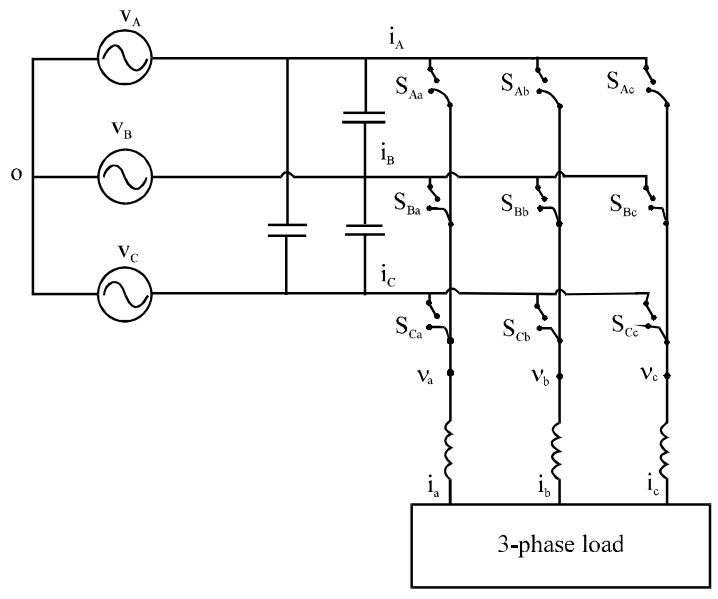

Fig. 1: Simplified representation of a matrix converter system

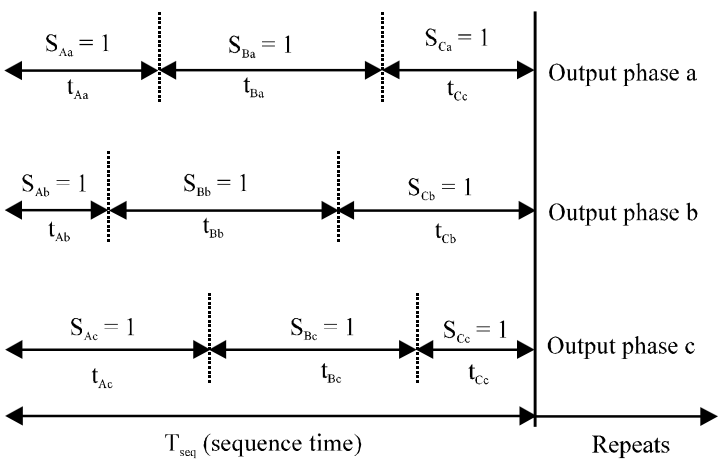

Fig. 2: General form of the switching pattern

should satisfy the following constraint equation (Huber and Borojevic, 1995; Wheeler et al., 2002):

$$
\mathrm{S}_{\mathrm{Aj}}+\mathrm{S}_{\mathrm{Bj}}+\mathrm{S}_{\mathrm{Cj}}=1
$$

The shape of the switching functions depends on the switching pattern used; a typical switching pattern is shown in Fig. 2 (Wheeler et al., 2002). By considering that the bidirectional power switches work with high switching frequency, a low-frequency output voltage of variable amplitude and frequency can be generated by modulating the duty cycle of the switches using their respective switching functions.

The switching frequency is usually $>20$ times, the output frequency in order to obtain an output voltage with low harmonic content (Imayavaramban et al., 2006). The low-frequency transfer matrix also known as modulation matrix (Arevalo, 2008; Shephered and Zhang, 2004) is defined by (Wheeler et al., 2002; Imayavaramban et al., 2006):

$$
M(t)=\left[\begin{array}{lll}
m_{A a}(t) & m_{B a}(t) & m_{C a}(t) \\
m_{A b}(t) & m_{B b}(t) & m_{C b}(t) \\
m_{A c}(t) & m_{B c}(t) & m_{C c}(t)
\end{array}\right]
$$

Where:

$$
\mathrm{m}_{\mathrm{kj}}(\mathrm{t})=\frac{\mathrm{t}_{\mathrm{kj}}}{\mathrm{T}_{\text {seq }}}
$$

The constraint equations for the matrix converter can be written as (Alesina and Venturini, 1981, 1989; Imayavaramban et al., 2006; Wheeler et al., 2002):

$$
\sum_{\mathrm{K}=A, \mathrm{~B}, \mathrm{C}} \mathrm{m}_{\mathrm{Ka}}(\mathrm{t})=\sum_{\mathrm{K}=A, \mathrm{~B}, \mathrm{C}} \mathrm{m}_{\mathrm{Kb}}(\mathrm{t})=\sum_{\mathrm{K}=\mathrm{A}, \mathrm{B}, \mathrm{C}} \mathrm{m}_{\mathrm{Kc}}(\mathrm{t})=1
$$

There are several modulation techniques used to obtain the modulation matrix, $M(t)$ such as Venturini method, Venturini optimum method, Scalar method and Space vector modulation method (Wheeler et al., 2002). In this study, the Venturini and Venturini optimum methods will be used. When the voltage gain ratio, $\mathrm{q}$ is $\leq 0.5$ for unity input displacement factor, the modulation duty cycles can be obtained using the Venturini method from the following compact form (Arevalo, 2008; Wheeler et al., 2002):

For:

$$
\mathrm{m}_{\mathrm{kj}}=\frac{\mathrm{t}_{\mathrm{kj}}}{\mathrm{T}_{\mathrm{seq}}}=\frac{1}{3}\left(\frac{1+2 v_{\mathrm{k}} v_{\mathrm{j}}}{\mathrm{V}_{\mathrm{im}}^{2}}\right)
$$

$$
\mathrm{K}=\{\mathrm{A}, \mathrm{B}, \mathrm{C}\}, \mathrm{j}=\{\mathrm{a}, \mathrm{b}, \mathrm{c}\}
$$

where, $\mathrm{v}_{\mathrm{k}}$ denotes the input voltages which are given by:

$$
\mathbf{v}_{\mathrm{i}}=\mathrm{V}_{\mathrm{im}}\left[\begin{array}{c}
\cos \left(\omega_{1} \mathrm{t}\right) \\
\cos \left(\omega_{1} \mathrm{t}+2 \pi / 3\right) \\
\cos \left(\omega_{1} \mathrm{t}+4 \pi / 3\right)
\end{array}\right]
$$

and $\mathrm{v}_{\mathrm{j}}$ denotes the reference output voltages which are given by:

$$
\mathbf{v}_{0}=\mathrm{qV}_{\text {im }}\left[\begin{array}{c}
\cos \left(\omega_{0} \mathrm{t}\right) \\
\cos \left(\omega_{0} \mathrm{t}+2 \pi / 3\right) \\
\cos \left(\omega_{0} \mathrm{t}+4 \pi / 3\right)
\end{array}\right]
$$

When the voltage gain ratio, $\mathrm{q}$ is $>0.5$ and $<\sqrt{3 / 2}$ for unity displacement factor, the modulation duty cycles can be obtained using the Venturini optimum method from the following compact form (Arevalo, 2008; Wheeler et al., 2002):

$$
\mathrm{m}_{\mathrm{Kj}}=\frac{1}{3}\left[\begin{array}{l}
1+\frac{2 v_{\mathrm{K}} v_{\mathrm{j}}}{\mathrm{V}_{\mathrm{im}}^{2}}+\frac{4 \mathrm{q}}{3 \sqrt{3}} \sin \left(\omega_{\mathrm{i}} \mathrm{t}+\beta_{\mathrm{k}}\right) \\
\sin \left(3 \omega_{\mathrm{i}} \mathrm{t}\right)
\end{array}\right]
$$


for $K=A, B, C ; j=\{a, b, c\} ; \beta_{K}=0,2 \pi / 3,4 \pi / 3$ for $K=A$, $B, C$, respectively. The reference output voltages, $v_{j}$ are obtained from (Alesina and Venturini, 1989; Arevalo, 2008; Imayavaramban et al., 2006; Wheeler et al., 2002):

$$
\mathbf{v}_{\mathrm{o}}=\mathrm{qV}_{\text {im }}\left[\begin{array}{c}
\cos \left(\omega_{0} \mathrm{t}\right)-\frac{1}{6} \cos \left(3 \omega_{0} \mathrm{t}\right)+\frac{1}{2 \sqrt{3}} \cos \left(3 \omega_{1} \mathrm{t}\right) \\
\cos \left(\omega_{0} \mathrm{t}+2 \pi / 3\right)-\frac{1}{6} \cos \left(3 \omega_{0} \mathrm{t}\right)+\frac{1}{2 \sqrt{3}} \cos \left(3 \omega_{1} \mathrm{t}\right) \\
\cos \left(\omega_{0} \mathrm{t}+4 \pi / 3\right)-\frac{1}{6} \cos \left(3 \omega_{0} \mathrm{t}\right)+\frac{1}{2 \sqrt{3}} \cos \left(3 \omega_{1} \mathrm{t}\right)
\end{array}\right]
$$

Inductive load model: The inductive load will be modeled in terms of the load current differential equation given by:

$$
\mathrm{D}[\mathrm{I}]=[\mathrm{VL}]+[\mathrm{LR}][\mathrm{I}]
$$

where:

$$
\begin{gathered}
{[\mathrm{I}]=\left[\begin{array}{l}
\mathrm{i}_{\mathrm{a}} \\
\mathrm{i}_{\mathrm{b}} \\
\mathrm{i}_{\mathrm{c}}
\end{array}\right]} \\
{[\mathrm{VL}]=\left[\begin{array}{c}
\mathrm{v}_{\mathrm{a}} / \mathrm{L} \\
\mathrm{v}_{\mathrm{b}} / \mathrm{L} \\
\mathrm{v}_{\mathrm{c}} / \mathrm{L}
\end{array}\right]} \\
{[\mathrm{LR}]=\left[\begin{array}{ccc}
-\mathrm{R} / \mathrm{L} & 0 & 0 \\
0 & -\mathrm{R} / \mathrm{L} & 0 \\
0 & 0 & -\mathrm{R} / \mathrm{L}
\end{array}\right]}
\end{gathered}
$$

System analysis: The performance of the system under consideration will be obtained for given voltage gain ratio, $q$, output frequency, $f_{0}$ and unity input power factor using the following procedure. When the voltage gain ratio, $\mathrm{q}$ is $\leq 0.5$ for given input voltages (Eq. 7), the reference output voltages are obtained using Eq. 8. The input and output voltages are used in Eq. 6 to obtain the modulation duty cycles of the matrix converter switches. When the voltage gain ratio $q$ is $>0.5$ and $\leq \sqrt{3 / 2}$, the reference output voltages are obtained from Eq. 10. The input and output voltages are used in Eq. 9 to obtain the modulation duty cycles of the switches. The modulation duty cycles are used to obtain the conduction periods of the switches during a switching interval, $\mathrm{T}_{\text {seq }}$ for a given switching frequency, $\mathrm{f}_{s}$. When the switching pattern shown in Fig. 2 is used the switching functions of the converter switches, $\mathrm{S}_{\mathrm{Kj}}$ can be obtained by comparing the modulation duty cycles with a saw tooth waveform whose frequency equals the switching frequency and its

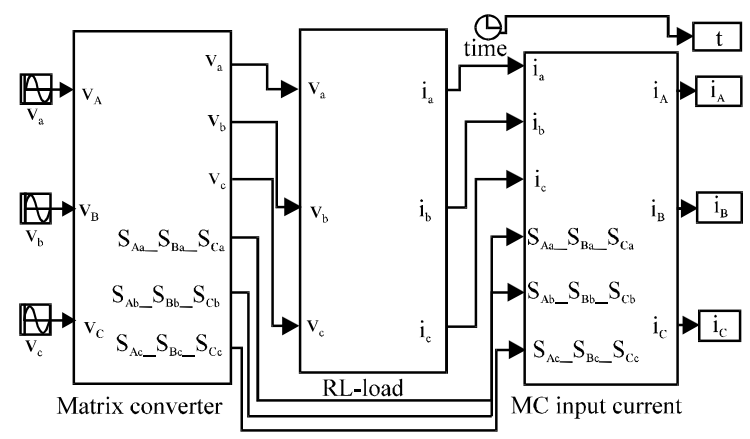

Fig. 3: System Simulink block diagram

$\mathrm{R}$ and $\mathrm{L}$ are the load resistance and inductance.

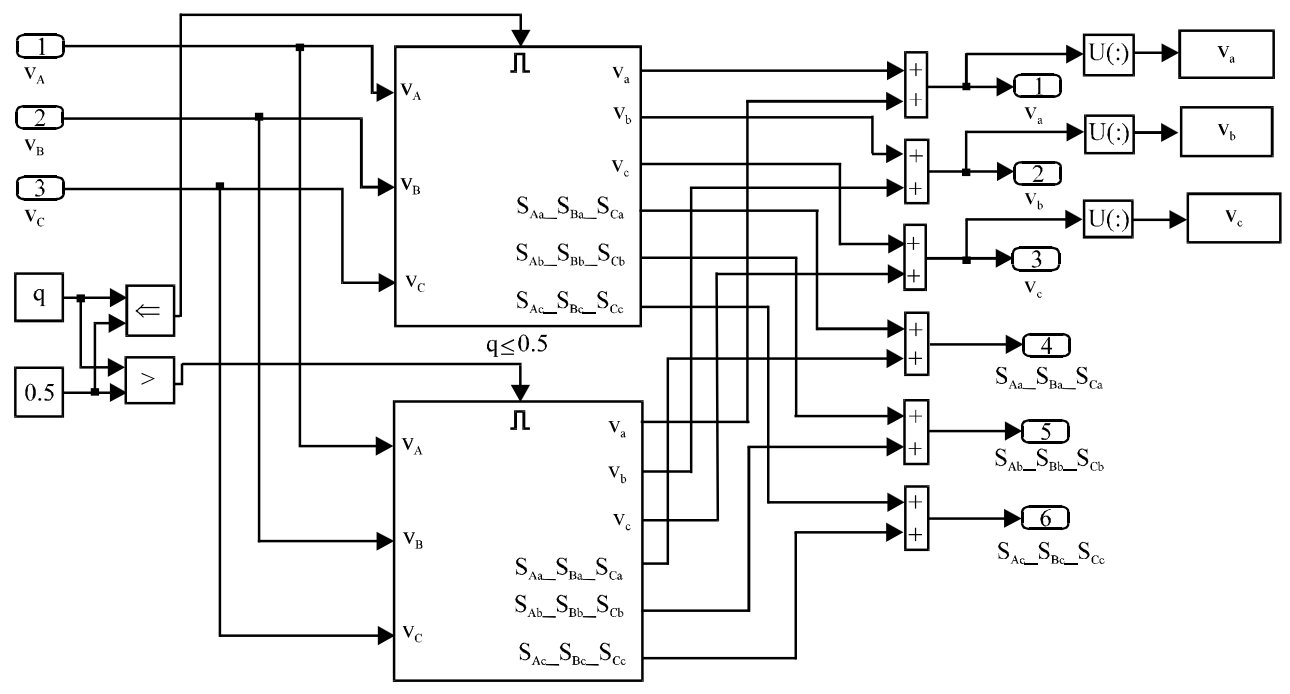

Fig. 4: Subsystem matrix converter 


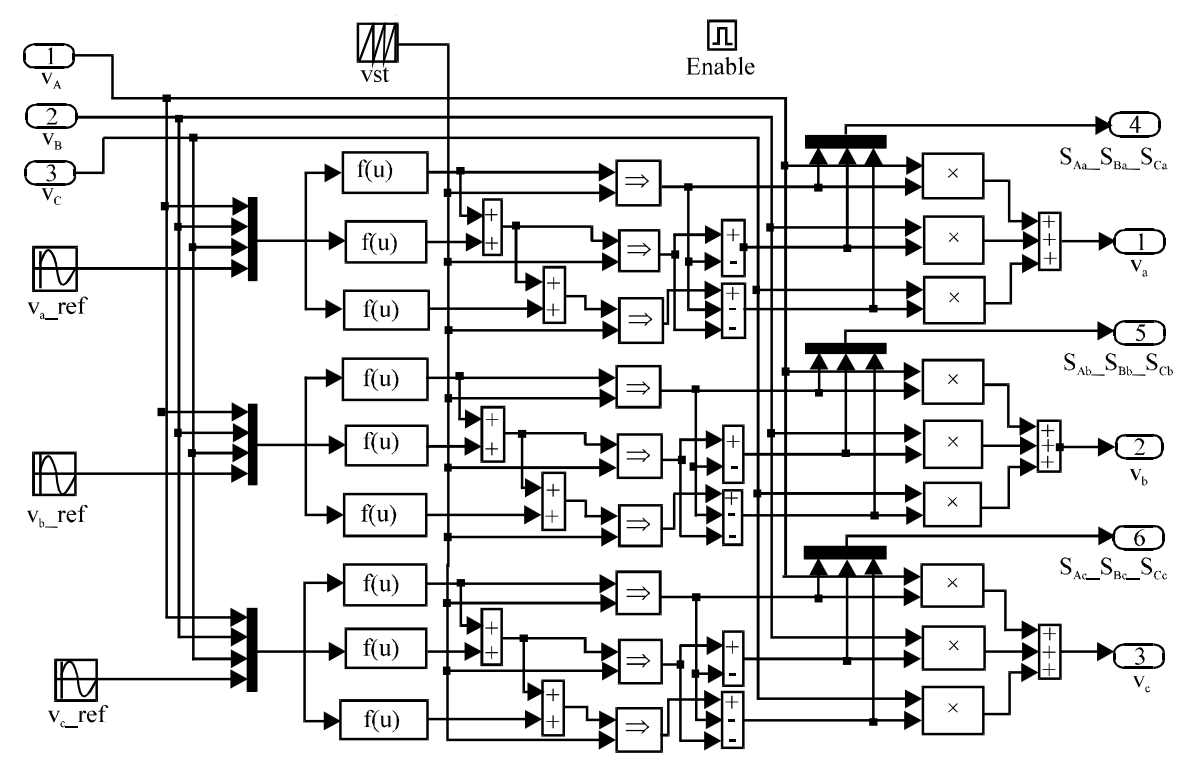

Fig. 5: Subsystem $\mathrm{q} \leq 0.5$

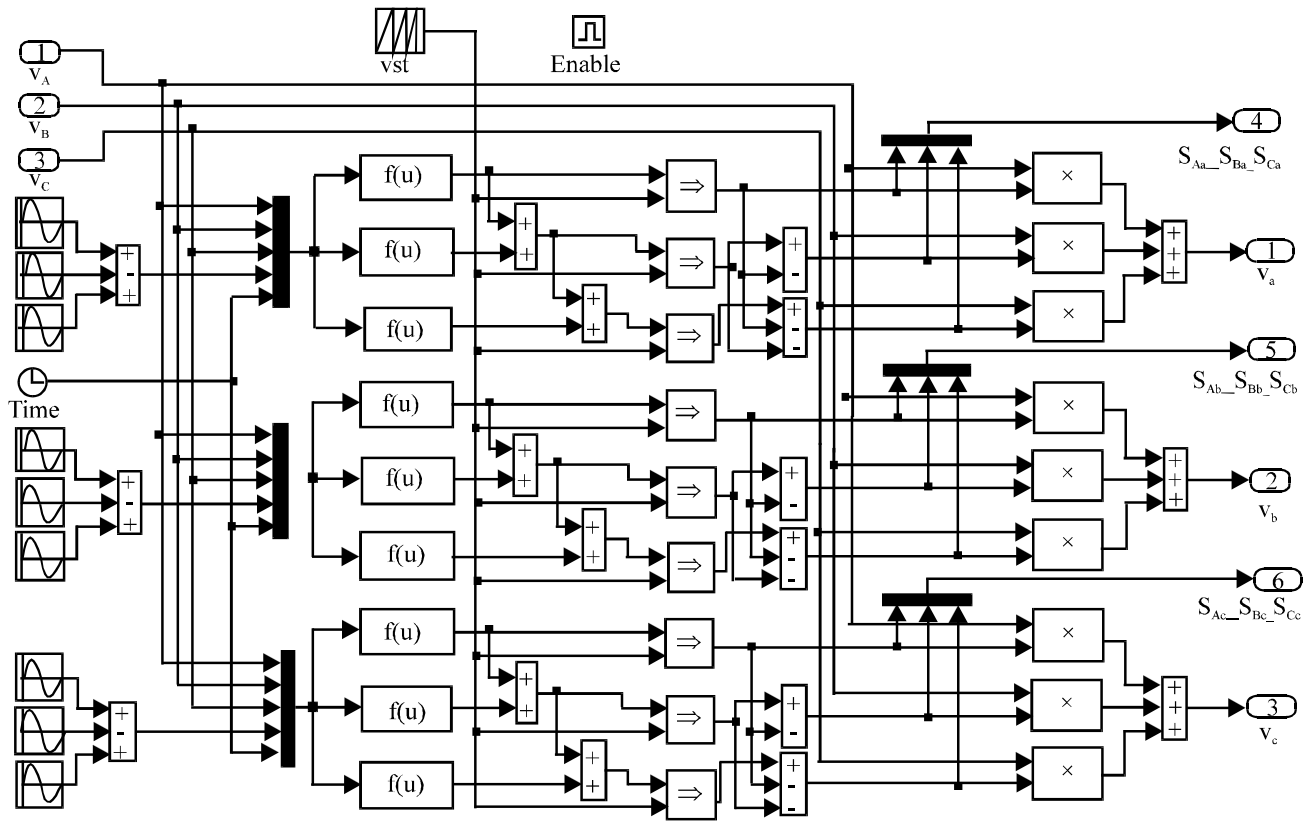

Fig. 6: Subsystem $0.5<\mathrm{q} \leq 0.866$

amplitude is unity. The switching functions and the input voltages are used in Eq. 1 to obtain the 3-phase output voltages of the matrix converter. The 3-phase output voltages are used in Eq. 11 to obtain the load currents. The corresponding input currents can be obtained using Eq. 2.

System simulation: The system under consideration is simulated using Matlab/Simulink software package. Figure 3 shows the Simulink block diagram of the system corresponding to the system of Fig. 1. This block diagram consists of three subsystems which are called matrix converter, RL-load and MC input current. The blocks labeled $\mathrm{v}_{A}, \mathrm{v}_{\mathrm{B}}$ and $\mathrm{v}_{C}$ represent the input voltage waveforms which are given in Eq. 7. The details of the subsystem matrix converter are shown in Fig. 4. It consists of two subsystems called $\mathrm{q} \leq 0.5$ and $0.5<\mathrm{q} \leq$ 0.866 . The details of these subsystems are shown in Fig. 5 and 6, respectively. In Fig. 5 and 6, the block labeled vst represents the saw tooth waveform and the block labeled 


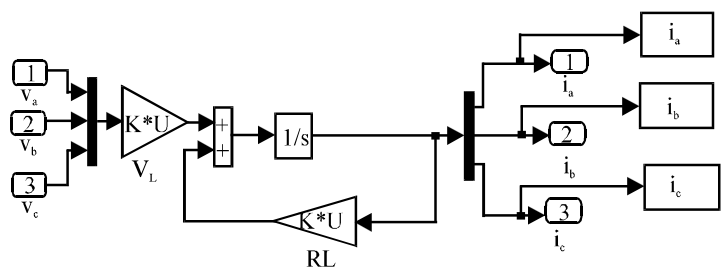

Fig. 7: Subsystem RL-load

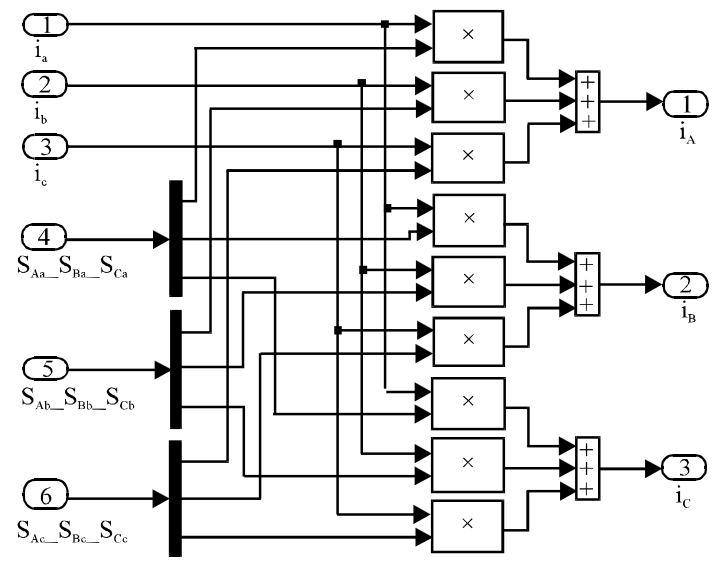

Fig. 8: Subsystem MC input current

enable is used to enable the subsystem output to be used when its input equals to unity otherwise the output will be disabled. Figure 5 represents Eq. 1, 6 and 8. Figure 6 shows Eq. 1,9 and 10. Figure 7 shows the details of the subsystem RL-load shown in Fig. 3. It represents Eq. 11. Figure 8 shows the details of the subsystem MC input current of Fig. 3. It represents Eq. 2.

\section{RESULTS AND DISCUSSION}

Results are obtained for the system under consideration with a voltage gain ratio $\mathrm{q}=0.4,100 \mathrm{~Hz}$ output frequency, $5 \mathrm{kHz}$ switching frequency, $230 \mathrm{~V}$ input voltage (peak value), $50 \mathrm{~Hz}$ input frequency, $10 \Omega$ load resistance and $20 \mathrm{mH}$ load inductance. Figure 9 and 10 show the output voltage and current waveforms of the matrix converter, respectively.

The obtained output current waveforms are compared with those obtained in reference (Imayavaramban et al., 2006) as shown in Fig. 10 in order to validate the simulation process. It is found that the two sets of results are almost identical.

It can be noted from Fig. 10 that the output current waveforms are approximately sinusoidal waveforms therefore they have low harmonic content. Another set of results is obtained for the system under consideration

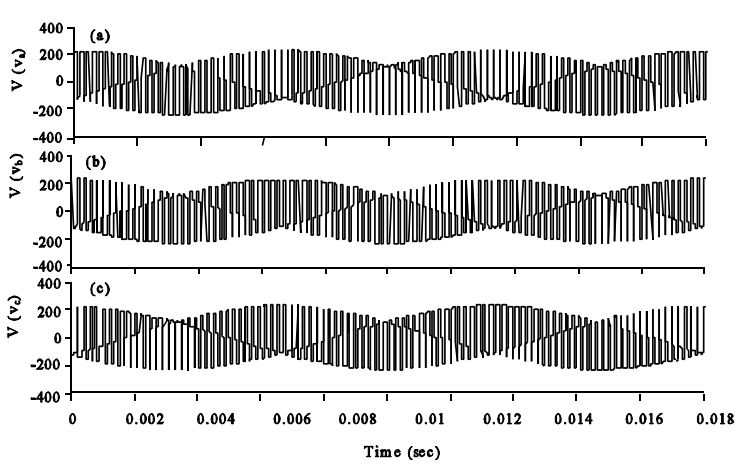

Fig. 9: Output voltage waveforms at $\mathrm{q}=0.4, \mathrm{f}_{0}=100 \mathrm{~Hz}$

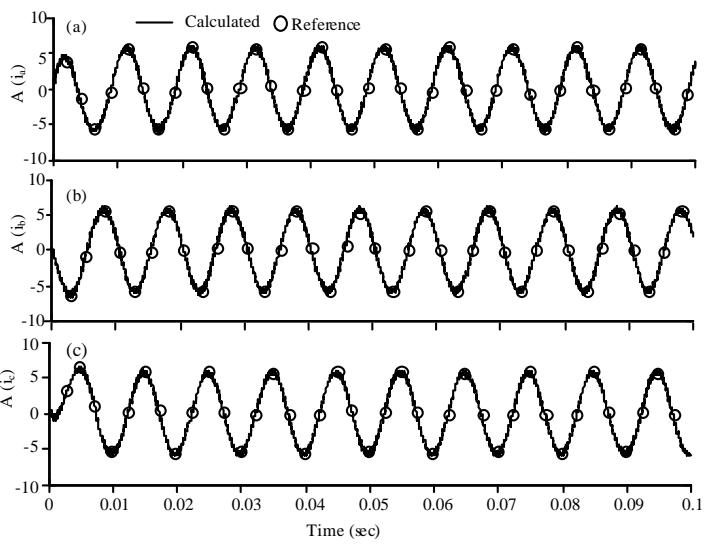

Fig. 10: Output current waveforms at $\mathrm{q}=0.4, \mathrm{f}_{0}=100 \mathrm{~Hz}$

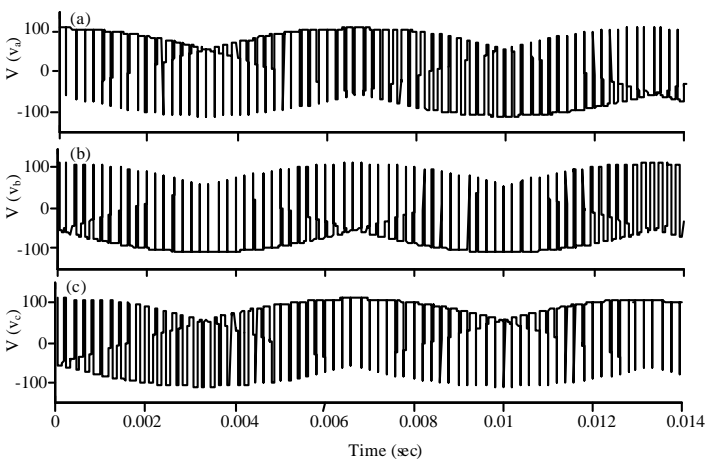

Fig. 11: Output voltage waveforms at $\mathrm{q}=0.85, \mathrm{f}_{0}=30 \mathrm{~Hz}$

with a voltage gain ratio $\mathrm{q}=0.85,30 \mathrm{~Hz}$ output frequency, $5 \mathrm{kHz}$ switching frequency, $110 \mathrm{~V}$ input voltage (peak value) and with the same values used for previous case for the input frequency, load resistance and load inductance. Figure 11 and 12 show the output voltage and current waveforms of the matrix converter, respectively. The obtained output current waveforms are compared with those obtained in reference (Imayavaramban et al., 2006) as shown in Fig. 12 in order 


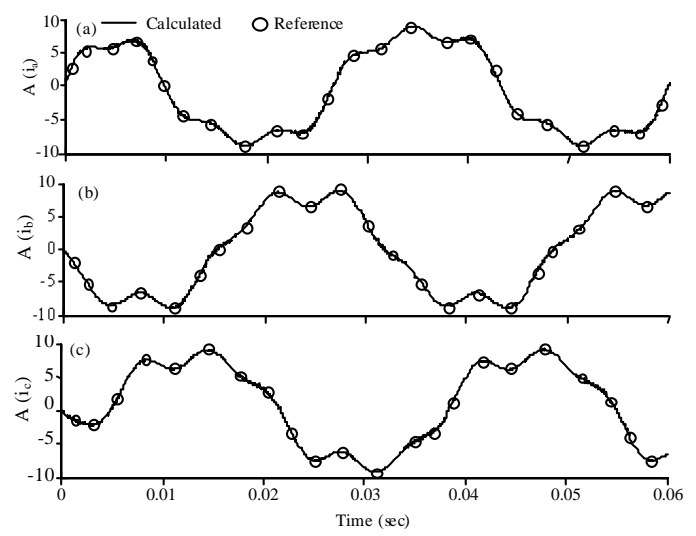

Fig. 12: Output current waveforms at $q=0.85, \mathrm{f}_{0}=30 \mathrm{~Hz}$

to validate the simulation process. It is found that the two sets of results are almost identical. Figure 12 shows that the output current waveforms are more distorted compared to those obtained for the 1st case (Fig. 10).

\section{CONCLUSION}

A Matlab/Simulink block diagram has been constructed in detail for a matrix converter/an inductive load system. The constructed block diagram for the matrix converter can be used to study and analyze the performance of any application in which the matrix converter is used whether the voltage gain ratio $\mathrm{q} \leq 0.5$ or $0.5<\mathrm{q} \leq 0.866$. The obtained results are almost identical with those obtained from the literature which proves the validity of the simulation using Matlab/Simulink package.

\section{REFERENCES}

Alesina, A. and M. Venturini, 1981. Solid-state power conversion: A fourier analysis approach to generalized transformer synthesis. IEEE Trans. Circuits Syst., 28: 319-330.

Alesina, A. and M.G.B. Venturini, 1989. Analysis and design of optimum-amplitude nine switch direct AC-AC converters. IEEE Trans. Power Electron., 4: 101-112.

Altun, H. and S. Sunter, 2003. Matrix converter induction motor drive: Modelling, simulation and control. Elect. Eng., 86: 25-33.
Arevalo, S.L., 2008. Matrix converter for frequency changing power supply applications. Ph.D. Thesis, University of Nottingham.

Arevalo, S.L., P. Zanchetta, P.W. Wheeler, A. Trentin and L. Empringham, 2010. Control and implementation of a matrix-converter-based AC ground power-supply unit for aircraft servicing. IEEE Trans. Ind. Electron., 57: 2076-2084.

Bradaschia, F., M.C. Cavalcanti, F. Neves and H. De Souza, 2009. A modulation technique to reduce switching losses in matrix converters. IEEE Trans. Ind. Electron., 56: 1186-1195.

Cardenas, R., R. Pena, P. Wheeler, J. Clare and G. Asher, 2009. Control of the reactive power supplied by a WECS based on an induction generator fed by a matrix converter. IEEE Trans. Ind. Electron., 56: 429-438.

Huber, L. and D. Borojevic, 1995. Space vector modulated three-phase to three-phase matrix converter with input power factor correction. IEEE Trans. Ind. Applic., 31: 1234-1246.

Imayavaramban, M., A.V.K. Chaithanya and B.G. Fernandes, 2006. Analysis and mathematical modeling of matrix converter for adjustable speed AC drives. Proceedings of Power Systems Conference and Exposition (PSCE), Oct. 29-Nov. 1, Atlanta, GA., pp: 1113-1120.

Shephered, W. and L. Zhang, 2004. Power Converters Circuits. Marcel Dekker Inc., New York.

Sunter, S. and H. Altun, 2005. Control of a permanent magnet synchronous motor fed by adirect AC-AC converter. Electr. Eng., 87: 83-92.

Vargas, R., U. Ammann and J. Rodriguez, 2009. Predictive approach to increase efficiency and reduce switching losses of matrix converters. IEEE Trans. Power Electron., 24: 894-902.

Vargas, R., U. Ammann, B. Hudoffsky, J. Rodriguez and P. Wheeler, 2010. Predictive torque control of an induction machine fed by a matrix converter with reactive input power control. IEEE Trans. Power Electron., 25: 1426-1438.

Wheeler, P.W., J. Rodriguez, J.C. Clare, L. Empringham and A. Weinstein, 2002. Matrix converters: A technology review. IEEE Trans. Ind. Electron., 49: $276-288$. 